\title{
Os CAPS e o Trabalho em Rede: Tecendo o Apoio Matricial na Atenção Básica
}

CAPS and networking: constructing matricial support in basic health care

Los CAPS y el trabajo en red: Tejiendo el apoyo matricial en la atención básica
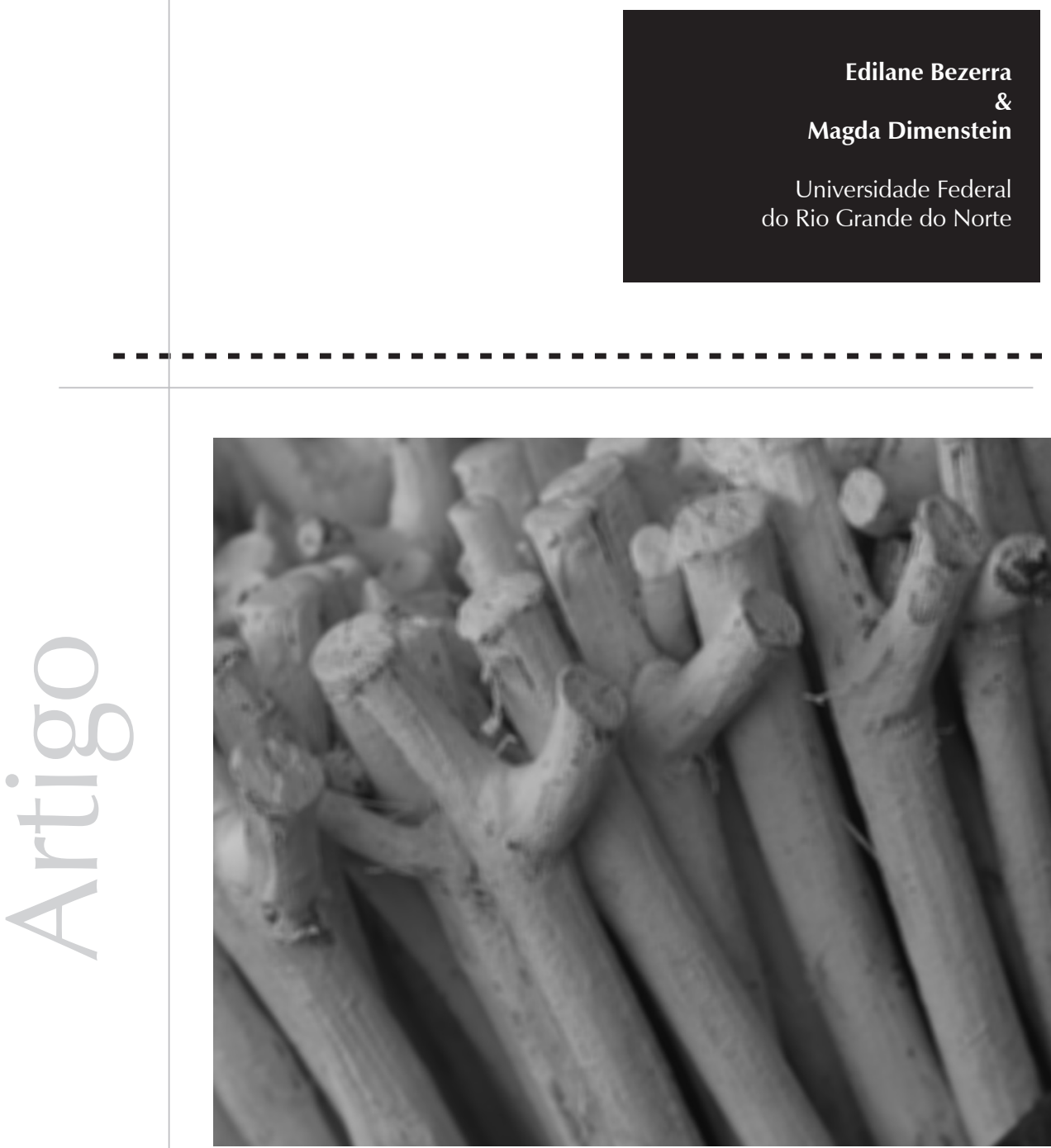
Resumo: A reforma psiquiátrica sinaliza a urgente articulação entre saúde mental e atenção básica na tentativa de avanço do processo de desinstitucionalização. Este estudo resulta de uma investigação junto a trabalhadores de saúde mental inseridos em CAPS II e Ad sobre a proposta de matriciamento às equipes de PSF. A Secretaria Municipal de Saúde de Natal pretende, com a implantação do apoio matricial, ampliar a rede de serviços substitutivos, melhorar o funcionamento dos atuais equipamentos e capacitar os profissionais de ambos os níveis de atenção, objetivando a ampliação do acesso aos serviços e os cuidados em saúde mental. Foram observados os seguintes aspectos: articulação precária entre os CAPS e a rede de atenção básica, necessidade de repensar a função dos CAPS na rede e rever o modelo de funcionamento ambulatorial pregnante e a formação acadêmica dos profissionais, que se revela insatisfatória para o cuidado aos portadores de transtornos mentais.

Palavras-chave: Reforma psiquiátrica. Saúde mental. Apoio matricial. CAPS. Atenção básica.

\begin{abstract}
The Psychiatric Reform proposes the articulation between mental health and basic health care as a step in the process of deinstitutionalization. This study presents the results of an investigation conducted with mental health workers in the CAPS regarding the matricial process in the Family Health teams. With the implementation of the matricial support, the Natal Secretariat of Health aims to extend the substitutive network services and the professional training for both levels of care, with the objective of widening the access of care services in mental health. The following aspects were observed: the precarious articulation between the CAPS units and the basic health care network; the need to review the function of the CAPS units within the network and their model of ambulatory care, and the academic formation of the health professionals that is unsatisfactory for the care of individuals with mental disturbances.
\end{abstract}

Keywords: Psychiatric reform. Mental health. Matricial support. CAPS. Basic care.

Resumen: La reforma psiquiátrica señaliza la urgente articulación entre salud mental y atención básica en el intento de avance del proceso de desinstitucionalización. Este estudio resulta de una averiguación junto a trabajadores de salud mental inseridos en CAPS II y Ad sobre la propuesta de vuelta a las matrices de los equipos de PSF. La Secretaría Municipal de Salud de Natal pretende, con la implantación del apoyo matricial, ampliar la red de servicios sustitutivos, mejorar el funcionamiento de los actuales equipos y capacitar los profesionales de ambos los niveles de atención, objetivando la ampliación del acceso a los servicios y los atenciones en salud mental. Fueron observados los siguientes aspectos: articulación precaria entre los CAPS y la red de atención básica, necesidad de recapacitar la función de los CAPS en la red y rever el modelo de funcionamiento ambulatorial de pregnancia y la formación académica de los profesionales, que se revela insatisfactoria para el cuidado a los portadores de trastornos mentales.

Palabras-clave: Reforma psiquiátrica. Salud mental. Apoyo matricial. CAPS. Atención básica.

Este artigo pretende discutir a implantação da proposta do apoio matricial em saúde mental segundo trabalhadores de CAPS do Município de Natal-RN. A atual política de saúde mental no Brasil, alinhada aos pressupostos da reforma psiquiátrica, propõe a progressiva substituição dos hospitais psiquiátricos por uma rede de serviços de atenção em saúde mental constituída por Centros de Atenção Psicossocial (CAPS), ambulatórios de saúde mental, residências terapêuticas, centros de convivência e cultura, serviços de saúde mental, emergências psiquiátricas em hospitais gerais e atendimento em saúde mental na rede básica de saúde.

A rede de atenção à saúde mental no Brasil está integrada ao Sistema Único de Saúde, e sua característica é essencialmente pública e de base municipal (Ministério da Saúde, 2005). Embora a atenção em saúde mental seja tarefa de uma rede articulada de serviços, essa articulação deve incluir os recursos da comunidade para se constituir em verdadeiros espaços de inclusão na cidade destinados às pessoas com transtornos mentais. 
No primeiro governo do atual Presidente Luís Inácio Lula da Silva, o processo de desinstitucionalização avançou significativamente, sobretudo com a instituição, pelo Ministério da Saúde, de mecanismos para a redução gradual e planejada de leitos no País e a expansão de serviços substitutivos ao hospital psiquiátrico. De acordo com o Relatório de Gestão 2003 a 2006 (Ministério da Saúde, 2007), nesse período, o Programa Nacional de Avaliação do Sistema Hospitalar/Psiquiatria (PNASH/ Psiquiatria) - primeiro processo avaliativo sistemático e anual dos hospitais psiquiátricos no Brasil, instituído em 2002 - e o Programa Anual de Reestruturação da Assistência Hospitalar Psiquiátrica no SUS - PRH estratégia de redução progressiva e pactuada de leitos a partir dos macro-hospitais, instituída em 2004 - foram os principais mecanismos de avaliação e redução de leitos psiquiátricos, o que muda o perfil da rede de hospitais psiquiátricos.

Embora em ritmos diferenciados, a redução do número de leitos psiquiátricos vem se efetivando em todos os Estados brasileiros, sendo, muitas vezes, esse procedimento o desencadeador do processo de reforma (Ministério da Saúde, 2005). No Rio Grande do Norte/RN, os hospitais de médio porte são minoria, e os de grande porte representam quase $1 / 3$ do quantitativo de hospitais existentes. O número de hospitais do RN credenciados no SUS segundo o porte é: pequeno ( $<50$ leitos) 10, médio (50 a 149 leitos) 6, grande ( $>=150$ leitos) 8 . Esses hospitais estão distribuídos em quatro macrorregiões: Natal, Mossoró, Caicó e Pau dos Ferros (Secretaria Municipal de Saúde de Natal, 2007). Em relação a outros Estados brasileiros, observa-se na região um esforço para que tal redução de leitos ocorra de forma efetiva e planejada, de modo a não provocar a falta de assistência de modo brusco.

De acordo com a Portaria GM no 1.101, de 11 de julho de 2002, o número de leitos recomendado é de 2 a 3,0 por 1.000 habitantes. Segundo o Plano Diretor de Regionalização-PDR, o Município de Natal é referência para todo o Estado, sobretudo em alta complexidade, que disponibilizou 1907 leitos para os seus munícipes e para os referenciados (Secretaria Municipal de Saúde de Natal, 2007). Sabe-se que, no RN, o número de leitos ainda não é adequado, e faz-se necessária uma substituição gradual e uma expansão cada vez maior de serviços substitutivos, ampliando, dessa forma, a assistência à saúde mental no RN.

É importante destacar que a Política Nacional de Saúde Mental vem trabalhando nos últimos anos com o conceito de leitos de atenção integral em saúde mental (hospitais gerais, CAPS III, leitos dos serviços hospitalares de referência para álcool e drogas), que se associam aos leitos de hospitais de pequeno porte, onde estes existirem. A tendência é de que essa rede de leitos de atenção integral, na medida em que se expande, se apresente como substitutiva à internação em hospitais psiquiátricos convencionais. Os recursos para a atenção hospitalar são insuficientes, e isso se manifesta no pagamento de procedimentos de média complexidade por valores muito abaixo dos seus custos. Devemos considerar, porém, que a pressão para que os leitos sejam reduzidos deve ser constante. Contudo, para avançarmos ainda mais na política de redução de leitos, teremos que ousar na expansão da 
rede substitutiva e no fortalecimento da saúde mental na atenção básica.

Nesse sentido, surgiu a estratégia institucional conhecida por apoio matricial (AM), que objetiva assegurar retaguarda especializada a equipes e profissionais encarregados da atenção em saúde mental. Visa a favorecer a co-responsabilização entre as equipes e a diversidade de ofertas terapêuticas através de um profissional de saúde mental que acompanhe sistematicamente as UBS/USF e permite o conhecimento da demanda em saúde mental que chega à atenção básica, bem como sobre os usuários, as famílias e o território, propondo que os casos sejam de responsabilidade mútua. O AM é um regulador de fluxos que promove uma articulação entre os equipamentos de saúde mental e as Unidades Básicas de Saúde (UBS) (Campos \& Domitti, 2007). Permite, além disso, diferenciar os casos que realmente precisam ser atendidos nos serviços especializados e os que podem ser acompanhados pelo PSF, ou pelo menos ser acolhidos momentaneamente por esses profissionais.

A literatura científica sobre o apoio matricial aponta o Município de Campinas/SP como um expoente em relação à saúde mental, com estudos pioneiros e avanços significativos na rede de saúde local (Figueiredo, 2006). Nesse Município, apostou-se na organização da saúde mental na rede básica através do AM, principalmente pela sua potencialidade para criar uma assistência mais integrada, desconstruindo a lógica do encaminhamento. O Projeto Paidéia de Saúde da Família (Campos, 2003) é referência em saúde, tendo sido aí implantado em 2001. Desde então, observa-se uma melhoria na assistência, com resultados favoráveis em relação à rede de saúde do Município.

Em Natal-RN, desde 2006, vem ocorrendo um processo de implementação do apoio matricial (AM), que articula a rede de serviços substitutivos e as Unidades de Saúde da Família/USF. As discussões acerca do AM em Natal estão em fase inicial, e avançam significativamente nesse processo. Tal projeto está em curso em 13,6\% da rede, tendo sido iniciado pelas unidades de Saúde da Família. São apoiadas pelos CAPS, atualmente, 02 unidades no Distrito Sanitário Oeste, 03 unidades no Distrito Sanitário Leste e uma no Distrito Norte I. Está previsto um percentual de mais 30\% de unidades apoiadas até 2008 (Secretaria Municipal de Saúde de Natal, 2006). A coordenação em saúde mental do Município pretende, com o apoio matricial, ampliar a rede em saúde mental, capacitar os profissionais envolvidos e garantir o acesso para todos os usuários que necessitem de atenção em saúde mental.

\section{Instrumento e participantes}

Esta investigação foi realizada nos 04 CAPS da cidade de Natal em 2006, sendo 02 CAPS II (Leste e Oeste) e 02 CAPS AD (Norte e Leste). O CAPS-i ainda não tinha sido inaugurado quando foi realizada a coleta de dados. Essa escolha ocorreu em virtude de os CAPS serem referência em saúde mental e assumirem um lugar estratégico na organização da rede de cuidados substitutiva; ademais, participam da proposta de matriciamento dando suporte, em saúde mental, às USF. Foi elaborado um roteiro de entrevista semiestruturada, visando a discutir alguns eixos 
temáticos. Foram feitas 17 entrevistas, no total, distribuídas entre as seguintes categorias profissionais: 7 psicólogos, 3 assistentes sociais, 3 enfermeiras, 3 psiquiatras e 1 nutricionista. Dentre esses profissionais, alguns exerciam o cargo de coordenação dos serviços. Dessa maneira, teremos como foco de discussão, especificamente, a articulação da rede de serviços e o lugar que o CAPS nela ocupa, as estratégias utilizadas pela SMS na implementação do AM e a importância da proposta, bem como as dificuldades e os desafios postos às equipes envolvidas.

\section{Resultados e análise}

Eixo 1: Forma de participação dos CAPS no processo de implementação do apoio matricial

Os CAPS estão participando ativamente da proposta de implementação do AM, principalmente os coordenadores dos serviços que buscam envolver todos os profissionais na discussão da proposta, fazendo com que todos possam participar dos encontros, fóruns e reuniões promovidos pela Secretaria Municipal de Saúde. Contudo, por ocupar, dentre os dispositivos de atenção à saúde mental, um lugar estratégico no processo da reforma psiquiátrica, os CAPS poderiam assumir um papel mais ativo na articulação da atenção básica com a saúde mental, atuando como ordenador da rede de cuidados. Observamos que, apesar da consolidação de novos modos de cuidar em saúde mental, o CAPS sofre as conseqüências da desarticulação das políticas públicas para o setor nos níveis local, estadual e federal. Tal desarticulação aparece mais claramente na questão do encaminhamento e no sistema de referência e contra-referência, que o apoio matricial pretende desconstruir. Com a implementação do AM, a ênfase é dada às discussões, pois os profissionais dos CAPS buscam se reunir com as equipes das UBS e discutir os casos de saúde mental, colher a história do usuário e tentar encontrar saídas em conjunto. Verificou-se, no relato abaixo, a importância da responsabilização compartilhada dos casos:

\begin{abstract}
A gente busca trabalhar sempre de forma integrada, todos os serviços; eu acho que essa denominação de responsabilidade compartilhada leva a isso, nós profissionais trabalhando de maneira conjunta, sem essa lógica do encaminhamento, iremos conseguir, estando mais apto e mais receptivo para o serviço, para o funcionamento da rede, pra se trabalhar em rede. (Enfermeira)
\end{abstract}

A organização da rede precisa também contemplar a necessidade de modificar o modo de gerir os serviços e de trabalhar em saúde; para isso, segundo Merhy (2006), seria necessário reconstruir a idéia do trabalhador em saúde, procurando a configuração do trabalhador coletivo e construindo um processo que propague os espaços institucionais com a presença do conjunto de atores realmente interessados na saúde, em particular, os usuários.

Eixo 2: Importância do apoio matricial para a rede de saúde

Os entrevistados dos serviços consideraram o AM uma estratégia para melhorar o fluxo resolutivo da rede, interligando diferentes dispositivos e excluindo a lógica dos encaminhamentos, por meio da articulação e do assessoramento da rede básica através do princípio da territorialidade. Com isso, estão 
trabalhando de acordo com a proposta da SMS, mostrando tê-la compreendido.

De um modo geral, os entrevistados também apontam a importância da proposta do apoio matricial em se trabalhar o território, não ficando apenas no contexto do espaço físico do CAPS, ou seja, articulando-se com a rede de saúde como um todo e com toda a sociedade ao desempenhar uma assistência integral. Eles apontam também a troca de saberes e de experiências, além do assessoramento das unidades básicas, como uma contribuição possível pelo AM.

O apoio matricial cria uma dimensão melhor para o trabalho de território, principalmente em rede, e você poder ser apoiador e poder trocar a experiência de trabalho com as UBS. Tá trocando essa experiência e de certa forma assessorando essas equipes dando esse suporte que o apoio matricial aponta. (Assistente social)

Acho que os profissionais da saúde mental ainda não entenderam a importância desse AM. De um modo geral, tem muita gente que ainda não entendeu, tem dificuldade de aderir, de achar que isso é uma prioridade, que deve ser feito. Aqui no CAPS, a gente tem discutido muito e a equipe tem entendido isso, e a gente tá em processo de implementação. (Psiquiatra)

Eixo 3: Habilidades/conhecimentos que a equipe precisa ter para realizar o matriciamento

Os entrevistados afirmam que existe a necessidade de se ter uma visão ampla do processo saúde-doença, de se compreender o lugar da rede básica, de contribuir para as discussões nas UBS e de colocar a sua experiência e o seu conhecimento à disposição da saúde mental. O próprio discurso requer uma habilidade, a forma de se chegar às equipes de USF, de mostrar a importância do trabalho do apoiador, de modo que eles sejam articuladores na rede de serviços de saúde.

O AM poderá propiciar um espaço de trocas de experiências e de saberes no campo da saúde mental com outros profissionais da rede básica, sendo uma construção coletiva que favorece a co-responsabilização e a avaliação contínua no tratamento do usuário. Vejamos o que diz o entrevistado ao mencionar a importância de se ter a habilidade para trabalhar em grupo:

Em termos de habilidades, acho que a equipe do CAPS precisa, acho que ela já tem, é trabalhar em grupo, levar essa idéia do grupo pra o PSF, do trabalho com grupo, da inclusão social, de como esse trabalho pode ajudar para facilitar alguns tipos de intervenção, pois a demanda em saúde mental no PSF é expressiva. (Psiquiatra)

Eixo 4: Tipo de demanda que sugere a necessidade do trabalho do apoio matricial

Ao serem questionados sobre que tipo de demanda surge na atenção básica e sugere a necessidade do trabalho do AM, uma das entrevistadas afirma que estão avançando nas discussões sobre a proposta da SMS acerca do $\mathrm{AM}$, de modo que ainda não é possível traçar muitas considerações a esse respeito. Percebemos que há, de fato, um desconhecimento acerca dos problemas enfrentados cotidianamente pelos técnicos do PSF, de modo que os CAPS aparecem como realidades distantes dos serviços de atenção básica. Não há interface alguma entre tais níveis de atenção, não se conhecem as equipes presentes no território e nem a possibilidade de realização de trabalhos articulados. São instâncias distintas que não se comunicam. 
Entretanto, sabe-se que as equipes de atenção básica lidam cotidianamente com uma enorme demanda de saúde mental, com casos de violência, maus-tratos, abuso de drogas e psicotrópicos e depressão, dentre outras queixas. São demandas que produzem mal-estar nas equipes, pois, na maioria dos casos, elas se sentem despreparadas para lidar com essas questões. Quando se trata de crises psicóticas ou de aparecimento de transtornos mentais, a situação se agrava ainda mais. $\mathrm{O}$ intuito, dizem os entrevistados, é que os CAPS realmente possam chegar como apoiadores das equipes de PSF para que tais demandas de saúde mental possam ser atendidas também nas unidades básicas. Para tanto, é preciso conhecer o cotidiano dessas equipes, sair dos espaços institucionais já conhecidos e ousar novas formas de trabalho.

Eixo 5: Dificuldades em relação à implementação da proposta do apoio matricial

Existe uma série de obstáculos para se realizar o trabalho de articulação da rede de serviços, dentre eles, a inexistência de uma rede de atenção básica eficaz, a deficiência de suporte dos serviços existentes e o número insuficiente de profissionais. Como resultado, há uma demanda excessiva sobre as equipes, superlotação dos serviços e presença do encaminhamento para outros serviços como forma de atenção. Os técnicos assinalam que os CAPS sequer estão conseguindo atender a demanda que chega até o serviço, de modo que questionam a efetividade real da proposta de matriciamento. Outro aspecto é a necessidade de se ter mais profissionais no serviço (CAPS) que de fato queiram se envolver com o AM, porque, para que este seja resolutivo em suas ações, demanda a participação de todos, uma mudança na lógica de organização do serviço. Observou-se no relato abaixo:

Acho que é fundamental você poder contar, tá amparado e não no desamparo de rede, acho que é isso o risco que corre, os CAPS não trabalhar em território, não implementar esse princípio que é a territorialidade. (Assistente social)

Por serem dificuldades estruturais, estas devem ser entendidas como efeitos das políticas econômicas, que são reflexos da economia mundial e que só podem ser enfrentadas mediante processos de envolvimento dos atores sociais na luta em defesa do SUS. Assim, verifica-se que a transformação da atenção depende da mudança de postura dos próprios profissionais, que não se vêem como atores sociais com potencial de transformar o quadro atual da saúde pública.

Durante os relatos, constatou-se a necessidade de uma qualificação na área da saúde mental. É reiterada a falta de capacitação necessária para agir e tomar decisões no campo da saúde mental, além da questão do tempo reduzido para a atenção da grande demanda. Justificam a sua dificuldade em realizar o matriciamento argumentando não ser por falta de interesse na área, “...não é que a gente não tenha vontade ou interesse, a gente quer fazer esse apoio, mas nós não temos tempo e acho que até falta preparação" (Assistente social).

Por outro lado, afirmam que o apoio matricial depende da responsabilização, depende da disponibilidade do profissional:

Eu acho que o apoio depende também da disponibilidade da gente, tem profissional que não têm habilidade pra realizar o trabalho do AM, tem profissional que tem o perfil de estar se comprometendo, se responsabilizando pelo usuário, e têm outros que não. (Assistente social) 
Alguns entrevistados sustentam, ainda, que o AM tem que ser processado de maneira mais clara pelas equipes para que os técnicos não o vejam como um trabalho a mais. Eles apontam o fato de não conseguirem dar conta do trabalho que realizam no CAPS, e, por outro lado, para conciliar esse trabalho com o de matriciamento, faz-se necessário definir quantas serão as equipes de PSF, os dias e os horários do trabalho de apoio. Os profissionais alegam que o tempo que permanecem no serviço não é suficiente para dar suporte às unidades de saúde. Indicam certo desconforto, temendo que ocorra uma sobrecarga de trabalho, já que existe uma escassez de funcionários no serviço. Ademais, outro aspecto levantado pelos coordenadores diz respeito a questões salariais, uma vez que já são mal remunerados para exercer o trabalho no CAPS. Atualmente, ainda se está definindo como irá acontecer o processo de matriciamento nas UBS, que está em fase inicial, como foi mencionado anteriormente.

Nesse sentido, algumas providências já foram tomadas, a começar por exigir a presença de todos os profissionais dos serviços substitutivos. A coordenação de saúde mental programou um encontro no mês de abril de 2007 para discutir o AM e solicitar a presença de todos os profissionais, tendo que suspender as atividades dos serviços durante a realização do encontro para poder contar com a participação de todos os trabalhadores dos serviços.

Diante das considerações mencionadas acima, a Secretaria Municipal de Saúde de Natal pretende atribuir uma gratificação para os apoiadores matriciais. Essa possibilidade vem sendo estudada durante os encontros realizados nos distritos sanitários e em reuniões feitas com os coordenadores dos CAPS sob a orientação do coordenador de Saúde Mental do Município. No entanto, apenas se pretende implantar tal gratificação, que, até a finalização deste estudo, não havia sido definida.

A articulação entre os diversos serviços nos diferentes níveis de atenção também é apontada como uma dificuldade. Os CAPS, que deveriam atuar como articuladores e ordenadores da rede, acabam centralizando a demanda e inserindo-se de forma muito tímida nos territórios e na comunidade. A forma como os serviços estão organizados, portanto, constitui-se em uma grande dificuldade para a atuação frente às demandas de SM.

Assim, percebeu-se, pelos discursos, que a maioria dos trabalhadores do CAPS tem um conhecimento da política de saúde mental e inclusive percebe o lugar do CAPS no interior dessa política. Os aspectos que merecem ser destacados dizem respeito ao envolvimento dos trabalhadores enquanto atores das ações em saúde mental, que exigem uma ampliação do campo de intervenção.

Alguns entrevistados relatam que tudo se resume em vontade política, e faz-se necessário dar aos profissionais estrutura e mais autonomia para solucionar os pequenos impasses que ocorrem no dia a dia na realização de algumas atividades, como, por exemplo, a compra de materiais para a realização das oficinas e a locomoção dos profissionais para a realização do trabalho do apoio matricial. Ressaltam os entrevistados que a estrutura da Secretaria de Saúde ainda é muito burocratizada, e, no que diz respeito 
Se, no campo da produção em geral, essa

maneira de operar a organização do trabalho traz problemas, em saúde, a situação é ainda mais complicada, e os resultados, medíocres; no caso do SUS, é mais grave ainda, pois é impossível transformar

práticas com esse tipo de condução política e técnica

(Campos, 2006; Merhy, 2002). à saúde mental, esta acaba não sendo vista como prioridade, já que existe o desinteresse da gestão local pela área de saúde mental e o conseqüente não investimento nas condições básicas de funcionamento (medicação, transporte, internet), além da falta de condição de trabalho (salários).

Percebeu-se que, de modo geral, alguns impasses estão relacionados às carências estruturais dos serviços e, principalmente, ao não-reconhecimento no âmbito de ações de saúde mental que deveriam se desenvolver no território sob a responsabilidade dos profissionais dessa forma, é importante que os profissionais se comprometam e se vejam como atores sociais, seja das práticas, seja das próprias políticas para que se possa realizar o trabalho de matriciamento. Contudo, fica evidente a necessidade de qualificação dos trabalhadores para a execução da política de saúde mental, pois, sem eles, não será possível consolidar a grande transformação que se pretende empreender.

Na reorganização dos serviços de saúde, deve-se refletir sobre a construção de uma rede de serviços territoriais de saúde mental com o intuito de substituir o tratamento em hospital psiquiátrico e avançar no processo de reforma psiquiátrica, sobretudo no Município de Natal-RN, região onde foi realizado o estudo em questão. Vejamos o seguinte discurso:

A maior dificuldade é a gente trabalhar em rede; muitas vezes, a gente faz exatamente o oposto, contribuindo pra que isso não aconteça. A primeira coisa que temos que fazer é organizar a rede, a articulação entre os serviços é fundamental. Alguns alegam o fato de não ter CAPS em todo o território como justificativa pra não fazer o seu trabalho. (Enfermeira)
A centralização dos processos políticos e a fragmentação do trabalho levam os profissionais ao desinteresse, à alienação e à ausência de responsabilidade em relação aos resultados finais. Se, no campo da produção em geral, essa maneira de operar a organização do trabalho traz problemas, em saúde, a situação é ainda mais complicada, e os resultados, medíocres; no caso do SUS, é mais grave ainda, pois é impossível transformar práticas com esse tipo de condução política e técnica (Campos, 2006; Merhy, 2002).

A construção dos espaços democráticos e dos atores necessários à construção do SUS não está plenamente contida na institucionalidade já produzida e consolidada no sistema. Novos arranjos políticos de gestão e de participação são, portanto, indispensáveis (Merhy, 2005). Nesse sentido, é fundamental o desenvolvimento de mecanismos que tenham como objetivo traduzir os princípios e diretrizes fundamentais para a implantação de um sistema de saúde universal que seja unânime a toda a população, transformando em práticas institucionais efetivas o direito à saúde.

Pelo fato de se tratar de uma estratégia recente no campo da saúde, percebe-se que o cotidiano dessa prática do AM encontra-se em processo de construção na rede. Contudo, a construção de uma rede de cuidados é fundamental para a consolidação da reforma psiquiátrica. Isso significa a articulação dos serviços de atenção à saúde mental com os da atenção primária, com outros setores de serviços públicos e, ainda, com quantos forem os recursos do território que possam, de alguma maneira, constituir-se em um conjunto vivo e concreto de referências capazes de acolher as pessoas com transtornos mentais (Ministério da Saúde, 2005). 
Entre os entrevistados, há certo consenso quanto à necessidade de articulação da rede de serviços, no entanto, foram poucas as ocasiões em que se revelou que essa articulação é percebida como uma das atribuições do CAPS: "O CAPS é isolado, quando você precisa dessas articulações com a rede pra ampliar a atenção em saúde mental, pra ampliar a questão da política de saúde mental, é difícil, chega a ser um problema" (Psicólogo).

Apesar de não ser esse o foco desta discussão, aspectos como a sobrecarga de trabalho foram levantados durante a entrevista por um dos entrevistados. Nesse sentido, entende-se a importância das relações entre o trabalho e a saúde, entretanto, em vez de se fazer uma análise em separado, é importante buscar, inicialmente, em meio ao conjunto dessas relações, até mesmo o modo como as dimensões da subjetividade aparecem na vida, ou seja, entende-se que seria necessária uma análise minuciosa e ao mesmo tempo global das condições e da organização do trabalho, considerando aspectos ligados às relações psicossocioafetivas que são estabelecidas (com) no trabalho: presença/ ausência da construção de sentido, da mobilização psíquica para o trabalho, dos coletivos de trabalho e da dinâmica do reconhecimento.

Uma entrevistada afirma o seguinte:

A princípio, sou eu que estou à frente das discussões sobre o AM; está sendo difícil a equipe caminhar, ter esse AM como movimento continuado. Alguns profissionais chegam até a falar em sobrecarga de trabalho, temem não conseguir dar conta do trabalho do CAPS e de matriciamento. (Assistente social)
O trabalho em saúde, para ser eficaz e resolutivo, dependerá sempre de certo coeficiente de autonomia dos agentes responsáveis pelas ações clínicas ou de saúde pública. A alienação, a falta de compromisso com a cura e com a promoção de saúde não são mais exceções à regra, e se constituem quase que em marcas da Medicina moderna e dos serviços de saúde em sentido mais geral. Ademais, a predominância dessas lógicas tem agravado em muito o fenômeno dos custos crescentes em saúde.

\footnotetext{
Na prática, essas propostas têm no pagamento por produção o principal mecanismo regulador do trabalho. Porém, se, por um lado, o pagamento por produção costuma aumentar a produtividade, por outro, quase nunca logra articular o trabalho a ser executado com compromissos sólidos com a cura e a recuperação dos usuários. (Campos, 2006, p. 230)
}

A noção de carga de trabalho tenta superar essa questão ao pressupor a análise do processo de trabalho de forma dinâmica e abrangente, incluindo não somente os aspectos técnicos presentes nos objetos e instrumentos do trabalho mas também a organização do trabalho. O conceito de carga de trabalho, como aponta Neves (1999), apresenta limites teóricos metodológicos sobretudo no que diz respeito à ênfase que é dada aos aspectos fisiológicos, o reducionismo da carga mental aos aspectos cognitivos, o direcionamento exclusivo aos aspectos nefastos do trabalho, a análise dos esforços especificamente referidos ao trabalho e a desconsideração da dimensão coletiva do trabalho, além da impossibilidade de obtenção de indicador geral.

Ao problematizar a relação trabalho-saúde, Dejours (1991) defende o ponto de vista de que o trabalho não é apenas fonte de doença e de infelicidade, mas, ao contrário, também 
pode ser operador de saúde e de prazer. Sendo assim, o trabalho, para o autor, nunca é neutro em relação à saúde, e pode favorecer tanto a doença quanto a saúde. Falar em saúde é falar em sentido no trabalho, em mobilização subjetiva - o que indica a luta (atravessada pelo sofrimento e pelo prazer) contra a doença e pela saúde, que jamais é definitivamente ganha.

Diante disso, faz-se necessário que os trabalhadores dos CAPS assumam que o apoio matricial faz parte de um dos vários dispositivos colocados pelo Ministério da Saúde (2003), pois o AM pretende superar a lógica da especialização e da fragmentação do trabalho da própria área de saúde mental através da responsabilização compartilhada dos casos, o que permite regular o fluxo de pacientes nos serviços. Nesse sentido, não podemos enxergar o apoio matricial como um trabalho a mais cujo efeito é produzir sobrecarga nos profissionais. É importante ressaltar que o CAPS tem uma função primordial ao articular a rede de atenção à saúde mental, além de ordenar e regular o trabalho em saúde mental e, sobretudo, ao lidar com o matriciamento. Há sobrecarga por parte de alguns profissionais devido à idéia equivocada que os mesmos têm do modelo ambulatorial pregnante atualmente no cotidiano dos CAPS, portanto, é preciso enfatizar ainda mais com as equipes dos CAPS e da atenção básica, para que, dessa maneira, se possa desconstruir essa idéia da sobrecarga e buscar um novo modo de organização do trabalho.

\section{Considerações finais}

Pelo fato de se tratar de uma estratégia recente no campo da saúde, verificamos que o AM se encontra em processo de construção na rede local. Porém, fica bastante nítida a importância dada ao AM, apesar de algumas dificuldades enfrentadas, sobretudo em relação à falta de capacitação na área de saúde mental, como bem ressaltam os entrevistados. Sabe-se que não é recente a tentativa de integrar a saúde mental nas práticas de médicos e de outros profissionais de saúde. Nos últimos anos, a reforma psiquiátrica brasileira tem avançado vigorosamente na reformulação da atenção em saúde mental, desconstruindo conceitos e práticas baseadas no isolamento e na exclusão social como formas de tratar a loucura.

Os CAPS surgem como uma proposta ousada de transformação ao tentar ganhar espaço em uma realidade antes alicerçada e restrita ao espaço hospitalar e com o poder de resolução centralizado no profissional médico. Uma atenção integral, como a pretendida pelo SUS, só poderá ser alcançada através da troca de saberes e práticas e de profundas alterações nas estruturas de poder estabelecidas, sendo instituída uma lógica do trabalho interdisciplinar por meio de uma rede interligada de serviços de saúde.

Se, por um lado, o CAPS ocupa um lugar de destaque na reorganização da assistência em saúde mental, por outro, pouco se investiu para que a rede básica acompanhasse os avanços da área de saúde mental em sua trajetória de transformações tecnoassistenciais. Entretanto, essa dicotomia traz desdobramentos importantes tanto para a configuração do SUS enquanto sistema unificado e integral como para a eficácia da rede básica e dos serviços substitutivos, dada a necessidade de estabelecer articulações necessárias para uma atenção resolutiva em saúde mental. 
Dessa maneira, a saúde mental na rede básica desempenha um papel fundamental ao contribuir com seus saberes para aumentar a capacidade resolutiva das equipes; nesse sentido, o apoio matricial pretende superar a lógica da especialização e da fragmentação do trabalho da própria área de saúde mental. O AM permite lidar com a saúde de uma forma ampliada e integrada através desse saber mais generalista e interdisciplinar, e, por outro lado, amplia o olhar dos profissionais da saúde mental através do conhecimento das equipes nas unidades básicas de saúde em relação aos usuários, às famílias e ao território, propondo que os casos sejam de responsabilidade mútua. O apoio matricial é um regulador de fluxo que permite entender e diferenciar os casos que realmente precisam ser atendidos pela saúde mental e os casos que podem ser acompanhados pelo PSF, ou pelo menos ser acolhidos momentaneamente por esses profissionais.

É importante destacar que o AM em saúde mental não pode ser reduzido apenas à atenção aos usuários e à capacitação/ supervisão dos profissionais, pois trata-se de uma tarefa complexa que, como foi colocado no decorrer deste trabalho, exige a implementação de medidas que consolidem o AM bem como uma política mais clara de assistência em saúde mental. Seria, portanto, um equívoco considerar o AM supervisão de caso, o que iria contra a proposta principal do AM, que é o envolvimento, a co-responsabilização pelos casos e a troca de saberes entre os profissionais.

Gomes (2006) destaca que, em se tratando de uma sociedade capitalista, na qual a lógica existente é a da individualidade, da segregação, da competição e das desigualdades sociais, dentre outras características, fica difícil a implementação de projetos que priorizem os princípios do SUS. Sendo assim, a lógica da co-responsabilização colocada pelo AM leva a questionamentos das especialidades pelos profissionais, a um modo de fazer diferenciado que ainda está sendo construído por todos os profissionais da saúde e que se contrapõem à idéia até então vigente de núcleos de especialidades.

Com base nessas considerações anteriores, Campos e Domitti (2007) consideram que nenhum especialista, de modo isolado, poderá assegurar uma abordagem integral. O AM pretende não só assegurar maior eficácia e eficiência ao trabalho em saúde mas também investir na construção de autonomia dos usuários. Faz-se necessário utilizá-lo como instrumento concreto e cotidiano, para que assim se possa atingir certo grau de reforma ou de transformação do modo como se organizam e funcionam serviços e sistemas de saúde.

Outro aspecto levantado diz respeito aos recursos humanos, ao número insuficiente de profissionais nos CAPS. Os entrevistados alegam que talvez não consigam conciliar o trabalho de apoiador com os atendimentos aos usuários do CAPS. Vale ressaltar que os apoiadores não são obrigados a reparar as falhas da rede no que tange a recursos humanos, e essa é uma posição que deve estar clara para todos os da rede de saúde.

Nessa compreensão, cabe mencionar que a proposta do Ministério da Saúde (2003) no tocante à organização das ações de AM recomenda que, nos Municípios onde haja CAPS e/ou outros equipamentos da saúde mental, o AM seja feito por tais equipes, que deverão reorganizar sua carga horária a fim de 
ter encontros semanais e formas de contato para demandas inesperadas ou intercorrências com as equipes da atenção básica. Em contrapartida, quando o número de CAPS for insuficiente na rede para tal apoio, devem ser implantadas equipes de matriciadores e/ ou haver o planejamento da expansão do número de serviços de saúde mental de base comunitária.

Desse modo, acreditamos ser de fundamental importância que a experiência do AM seja posta em análise entre seus atores, no intuito de ampliar sua potencialidade de agenciar mudanças nas práticas hegemônicas da saúde, no intuito de não se cometer o erro de torná-lo um modo cristalizado de trabalho.

Precisamos experimentar inovações, tecer novas redes de cuidado em saúde mental, colocar em questionamento nossos saberes e práticas, a fim de se fazer saúde de uma forma integral e efetiva, deixando de lado esse imobilismo das práticas no campo da saúde que atinge uma parte dos profissionais que insistem em não acreditar nos avanços alcançados no campo da saúde mental. Sabemos que ainda existe um amplo caminho a percorrer, além de avançarmos nas conquistas já alcançadas, como a redução considerável do número de leitos psiquiátricos e a expansão da rede substitutiva de serviços em saúde mental.

O apoio matricial, portanto, é um instrumento que vem se colocar no interior de um conjunto de estratégias fundamentais no processo da construção e da transformação da assistência em saúde mental, do qual o CAPS é um ponto fundamental. 
Edilane Bezerra*

Psicóloga pela Universidade Federal da Paraíba e mestranda do Programa de Pós-Graduação em Psicologia da UFRN; bolsista CAPES.

\section{Magda Dimenstein**}

Professora do Programa de Pós-Graduação em Psicologia da UFRN, Doutora em Saúde Mental pelo IPUB/UFRJ

\section{Endereco para envio de correspondência:}

*Rua Cônego Francisco de Lima, 384 Castelo Branco III, CEP: 58050-690 - João Pessoa-PB.

E-mail: edilane.bezerra@ig.com.br

** UFRN, CCHLA, Depto. de Psicologia, Campus Universitário, Lagoa Nova, CEP: 59.078-970 - Natal-RN.

E-mail: magda@ufrnet.br

Recebido 12/11/2007 Reformulado 14/07/2008 Aprovado 18/07/2008

Campos, G. W. S. (2003). Saúde paidéia (2a ed.). São Paulo: Hucitec.

Campos, G. W. S. (2006). Subjetividade e administração de pessoal: considerações sobre modos de gerenciar o trabalho em equipes de saúde. In E. E. Merhy \& R. Onocko (Orgs.), Agir em saúde: um desafio para o público (pp. 229-266). São Paulo: Hucitec.

Campos, G. V. S., \& Domitti, A. C. (2007). Apoio matricial e equipe de referência: uma metodologia para gestão do trabalho interdisciplinar em saúde. Cadernos de Saúde Pública, 23(2), 399-407.

Dejours, C. (1991, outubro). Normalidade, trabalho e cidadania [Entrevista]. Cadernos do CRP-06.

Figueiredo, M. (2006). Saúde mental na atenção básica: um estudo hermenêutico-narrativo sobre o apoio matricial na rede SUSCampinas-SP. Dissertação de Mestrado em Saúde Coletiva, Universidade Estadual de Campinas, Campinas, SP.

Gomes, V. G. (2006). Apoio matricial: estratégia de interlocução na rede de saúde de Campinas-SP. Trabalho de Conclusão de Curso de Aprimoramento em Saúde Mental, Faculdade de Ciências Médicas, Universidade Estadual de Campinas, Campinas, SP.

Merhy, E. E. (2002). Saúde: a cartografia do trabalho vivo. São Paulo: Hucitec.
Merhy, E. E. (2005). Engravidando as palavras: o caso da integralidade. In R. Pinheiro \& R. Mattos (Orgs.), Construção social da demanda (pp. 195-206). Rio de Janeiro: IMS-UERJ/ Abrasco.

Merhy, E. E. (2006). A rede básica como uma construção da saúde pública e seus dilemas. In E. E. Merhy \& R. Onocko (Orgs.), Agir em saúde: um desafio para o público (pp. 197-228). São Paulo: Hucitec.

Ministério da Saúde. Coordenação de Saúde Mental e Coordenação de Gestão da Atenção Básica. (2003). Saúde mental e atenção básica: o vínculo e o diálogo necessários. Brasília, DF: Autor.

Ministério da Saúde. (2005). Reforma psiquiátrica e política de saúde mental no Brasil. Brasília, DF: Autor.

Ministério da Saúde. (2007). Saúde mental no SUS: acesso ao tratamento e mudança do modelo de atenção. Brasília, DF: Autor.

Neves, M. Y. R. (1999). Trabalho docente e saúde mental: a dor e a delícia de ser (tornar-se) professora. Tese de Doutorado em Saúde Pública, Instituto de Psiquiatria, Universidade Federal do Rio de Janeiro, Rio de Janeiro.

Secretaria Municipal de Saúde de Natal. Prefeitura Municipal. (2006). Relatório anual de gestão. Natal: Autor.

Secretaria Municipal de Saúde de Natal. Prefeitura Municipal. (2007). (Re)desenhando a rede de saúde na cidade de Natal. Natal: Autor. 